\title{
Utilizing Powder XRD Technique to Analyze Polluted Soil
}

\section{Ashish Chauhan $^{1^{*}}$ and Bharti Mittu ${ }^{2}$}

${ }^{1}$ Small and Medium Pharmaceutical Industry Centre (SMPIC), Mohali, Punjab, India

${ }^{2}$ Central Instrumentation Department, NIPER, Mohali, Punjab, India

"Corresponding author: Ashish Chauhan, Small and Medium Pharmaceutical Industry Centre (SMPIC), Mohali, Punjab, India, Tel: +918665802345; E-mail: aashishchauhan26@gmail.com

Received: March 14, 2018; Accepted: March 18, 2018; Published: March 22, 2018

Copyright: (C) 2018 Chauhan A, et al. This is an open-access article distributed under the terms of the Creative Commons Attribution License, which permits unrestricted use, distribution, and reproduction in any medium, provided the original author and source are credited.

\section{Editorial}

Soil is an indispensible resource of the earth ecosystem. It is an amalgamation of organic matters, minerals, gases, liquids and organisms that supports life. Soil acts as a medium for the plants growth, a habitat for soil organisms, a recycling system for nutrients and organic matter and a regulator for water that plays a vital role in balancing the ecosystem.

Due to increase in the rate of consumption of resources with the radical increase in population, urbanization, large-scale industrialization, consumerism, industrial effluents are continuously discharged in wastewater. Owing to it, all the natural resources are in danger and polluted. The use of chemical pesticides, fertilizers, chemicals and pharmaceutical effluent has spoiled the soil to meet its dead end. The most lethal pollutants are bioactive chemicals causing creeping death.

There are various analytical techniques for the analysis of soil to evaluate the properties and its nutrient value. Some of the test are soil moisture content, soil $\mathrm{pH}$, electrical conductivity, organic matter (loss of ignition to estimate organic matter in non-calcareous soil), light fraction, water soluble organic carbon, microbial biomass $\mathrm{C} \& \mathrm{~N}$, available ammonium nitrate and nitrite by colorimetry, cations exchange capacity (CEC), exchangeable sodium percentage, sodium adsorption ratio, exchangeable cations by Atomic Absorption Spectrometry, texture analysis by hydrometer, Carbon, Nitrogen and Sulphur content by elemental analyzer, anion by ion chromatography $[1,2]$.

The drastic changes and advancement in the science and technology has developed various sophisticated analytical techniques to characterize the soil. Recently, many new techniques have been reported to access the soil. Some of these techniques are TG-IR (a combination of Thermogravimetric Analyzer and Infra Red Spectroscopy), Ultra Pressure Liquid Chromatography (UPLC), Fourier Transformer Infra Red Spectroscopy (FTIR) and Inductive Couple Plasma Mass Spectroscopy (ICP-MS) etc.

Powder XRD technique is a versatile technique that has immense applications. It is the prime instrument for the solid state characterization and soil mineralogical analysis. It is a tool for the identification of minerals in rocks and soils. Clay fraction of many soils is crystalline. Its usefulness extends to coarse soil fractions aswell. Due to pollution the soil properties such as mineralogical and chemical compositions, texture, arrangement of particles get altered. Immobilization of soil contaminants can be screened by XRD. X-ray diffraction pattern of a pure substances is like a fingerprint of substance. No two minerals have same spacing of inter atomic planes so the angle at which diffraction occurs can be used for its identification. A comparative study of the standard diffraction pattern of the soil with the test pattern can elucidate the difference.

$\mathrm{XRD}$ is the simple, easy, less time consuming means to evaluate the soil for its contamination. By the comparisons of the peaks intensity and peak positions the qualitative and quantitative analysis can be done. The technique has wide scope that remains unearthed for its use in soil characterization [3-6].

\section{References}

1. Chesworth W (2008) Encyclopedia of soil science. Dordrecht, The Netherlands. Springer. Retrieved 17 December 2017.

2. Chauhan A, Mittu B (2015) Soil Health - An Issue of Concern for Environment and Agriculture. Journal of Bioremediation \& Biodegredation 6: 1 .

3. Chauhan A, Singh B (2011) X-Ray Powder Diffraction Studies to Determine the Morphological Transformations in Hibiscus sabdariffa Graft Copolymers. International Journal of Polymer Analysis and Characterization 16: 319-328.

4. Chauhan A, Kaith B (2012) X-Ray Powder Diffraction Studies to Evaluate the Transition in Graft Copolymers Procured from Roselle Fiber. Journal of Natural Fibers 9: 87-97.

5. Chauhan A, Chauhan P (2017) XRD: A Pioneer Technique for Characterizing the Polymer and Fiber. Textile Science and Engineering, p: 7.

6. Chauhan A, Chauhan P (2014) Powder XRD technique and its applications in science and technology. Journal of Analytical \& Bioanalytical Techniques 5: 1 . 